\title{
STRATEGI PENINGKATAN MUTU GURU SEKOLAH DI LINGKUNGAN PESANTREN
}

\author{
Apud \\ Universitas Islam Negeri Sultan Maulana Hasanuddin Banten \\ J1. Jend. Sudirman No.30 Ciceri Serang Banten, Indonesia \\ e-mail: apud@uinbanten.ac.id
}

\begin{abstract}
This paper aims to describe the strategic efforts in improving the quality of school teachers in the pesantren environment, the problems of improving the quality of school teachers in the pesantren environment, the efforts and strategic steps of pesantren leaders in improving the quality of school teachers. The research method uses a descriptive-qualitative approach. Data collected through interviews, observations, and documentation. Data were then analyzed using Miles and Huberman analysis models. The results showed that the quality of school teachers in the pesantren environment could be done by fostering teacher quality, supervising teacher quality, providing facilities and infrastructure, planting commitments, and providing benefits.
\end{abstract}

Keywords: strategic, quality, pesantren environment

\section{PENDAHULUAN}

Profesionalisme guru menjadi salah faktor penentu keberhasilan lembaga pendidikan dalam menyelenggarakan proses pendidikannya. ${ }^{1}$ Guru dituntut untuk selalu profesional dalam bekerja dan menjalankan amanatnya sebagai agen pendidikan. ${ }^{2}$ Tanpa guru profesional proses pendidikan tidak akan dapat menghasilkan output pendidikan yang bermutu. ${ }^{3}$ Mutu pendidikan harus dikelola melalui serangkaian kegiatan yang menurut teori Trilogi Juran meliputi perencanaan mutu, pengendalian mutu, dan peningkatan mutu. ${ }^{4}$ Secara sistemik, mutu lembaga pendidikan

${ }^{1}$ Nani Mulyani, 'Pengembangan Profesionalisme Guru Pada Mtsn 1 Serang Melalui Peningkatan Kompetensi Profesional Dan Pedagogik', Tarbawi: Jurnal Keilmuan Manajemen Pendidikan 5, no. 01 (2019): 87-96; Juhji Juhji. "Profesi Pendidik dan Tenaga Kependidikan." Serang: Pusat Penelitian dan Penerbitan LP2M IAIN Sultan Maulana Hasanuddin Banten (2017); Istofa, Dian Nisa, and Marni Zulyanty. "Perencanaan Guru Madrasah Aliyah Jambi dalam Pembelajaran Matematika pada Kurikulum Tingkat Satuan Pendidikan." ANARGYA: Jurnal Ilmiah Pendidikan Matematika 1, no. 2 (2018): 103-109;.

2 Mu'izzuddin, Mochammad, Juhji Juhji, and Hasbullah Hasbullah. "Implementasi metode sorogan dan bandungan dalam meningkatkan kemampuan membaca kitab kuning." Geneologi PAI: Jurnal Pendidikan Agama Islam 6, no. 1 (2019): 43-50; JUHJI, Juhji, and Prasart NUANGCHALERM. "Interaction between science process skills and scientific attitudes of students towards technological pedagogical content knowledge." Journal for the Education of Gifted Young Scientists 8, no. 1 (2020): 1-16; Dewi Surani and Mifthahudin Mifthahudin, 'Kompetensi Guru Dan Motivasi Mengajar Guru Berpengaruh Terhadap Efektivitas Pembelajaran Di SMK Negeri 3 Kota Serang', Tarbawi: Jurnal Keilmuan Manajemen Pendidikan 4, no. 02 (2018): 149-58, https://doi.org/doi:10.32678/tarbawi.v4i02.1227; Maulana Amirul Adha, Achmad Supriyanto, and Agus Timan, 'Strategi Peningkatan Mutu Lulusan Madrasah Menggunakan Diagram Fishbone', Tarbawi: Jurnal Keilmuan Manajemen Pendidikan 5, no. 01 (2019): 11-22.

3 Apud, Apud. "Pengembangan Profesi Guru Madrasah Swasta Di Kota Serang." Nidhomul Haq: Jurnal Manajemen Pendidikan Islam 5, no. 1 (2020): 62-79; Noor, Wahyudin, and Juhji Juhji. "Integrasi Budaya Prestasi pada Fungsi Perencanaan Pembinaan Mutu Dosen." AL-TANZIM: Jurnal Manajemen Pendidikan Islam 4, no. 1 (2020): 1-12.

${ }^{4}$ Viswanath Venkatesh and Fred D. Davis, 'A Theoretical Extension of the Technology Acceptance Model: Four Longitudinal Field Studies', Management Science 46, no. 2 (2000): 186-204; V Gaspersz, Total Quality Managament (Jakarta: Gramedia Pustaka Utama, 2008); Apud Apud, 'Manajemen Mutu Pendidikan Man Insan Cendekia', Tarbawi: Jurnal Keilmuan Manajemen Pendidikan 4, no. 02 (2018): 171-90. 
ditentukan oleh mutu lulusan, mutu lulusan ditentukan oleh mutu pembelajaran, ${ }^{5}$ dan mutu pembelajaran ditentukan oleh mutu guru. ${ }^{6}$ Dengan demikian guru yang bermutu akan menghasilkan kinerja yang bermutu. Kinerja yang bermutu ditandai oleh sebuah proses pembelajaran yang bermutu, hasil belajar yang bermutu, dan tamatan yang bermutu bermuara pada mutu pendidikan. ${ }^{7}$

Untuk dapat menciptakan pendidikan yang bermutu, lembaga pendidikan dituntut untuk memiliki pemimpin yang mampu menginspirasi para guru agar bisa bekerja secara baik dan profesional dalam rangka mencapai tujuan organisasi. ${ }^{8}$ Kemampuan memimpin yang baik berkaitan dengan kemampuan untuk memimpin dan menginspirasi (inspiring) orang lain atau kelompok tanpa mengindahkan bentuk alasannya. ${ }^{9}$ Pemimpin merupakan pribadi yang memiliki kecakapan dan kelebihan khususnya kecakapan dan kelebihan pada satu bidang, sehingga dia mampu mempengaruhi orang lain untuk bersama-sama mencapai tujuan. ${ }^{10}$ Strategi pencapaian selalu diupayakan oleh pemimpin lembaga pendidikan dalam meningkatkan mutu guru. ${ }^{11}$

Kata strategi berasal dari kata Strategos dalam bahasa Yunani merupakan gabungan dari Stratos atau tentara dan ego atau pemimpin. ${ }^{12}$ Strategi adalah suatu proses penentuan rencana atau upaya para pemimpin puncak yang berfokus pada tujuan jangka panjang organisasi. ${ }^{13}$ Bentuknya berupa keputusan dan aksi yang ditujukan untuk mencapai tujuan (goal) dalam menyesuaikan sumber daya organisasi dengan peluang dan tantangan yang dihadapi dalam lingkungan organisasi. ${ }^{14}$ Suatu strategi mempunyai dasar atau skema untuk mencapai sasaran yang dituju. Melalui langkah strategis, pimpinan pesantren dan sekolah telah melakukan upaya dalam mewujudkan guru profesional, diantaranya: melalui beberapa pelatihan yang dilakukan di sekolah,

${ }^{5}$ Budi, Abdul Mufid Setia, and Apud Apud. "Peran kurikulum kulliyatul mu'allimin al-islamiyah (kmi) gontor 9 dan disiplin pondok dalam menumbuhkembangkan karakter santri." Tarbawi: Jurnal Keilmuan Manajemen Pendidikan 5, no. 01 (2019): 1-10; Juhji, Juhji. "Analyzing madrasah ibtidaiyah teacher candidates skill of technological pedagogical content knowledge on natural science learning." Al Ibtida: Jurnal Pendidikan Guru MI 6, no. 1 (2019): 1-18; Venkatesh and Davis, 'A Theoretical Extension of the Technology Acceptance Model: Four Longitudinal Field Studies'; Gaspersz, Total Quality Managament; Apud, 'Manajemen Mutu Pendidikan Man Insan Cendekia'.

${ }^{6}$ Dwiyama, Fajri. "Unsur Manajemen dalam Pengelolaan Lembaga Pendidikan Islam di Indonesia." Adaara: Jurnal Manajemen Pendidikan Islam 7, no. 1 (2018): 675-695; Venkatesh and Davis, 'A Theoretical Extension of the Technology Acceptance Model: Four Longitudinal Field Studies'; Gaspersz, Total Quality Managament; Apud, 'Manajemen Mutu Pendidikan Man Insan Cendekia'.

7 Zainal Aqib, Model-Model Media Dan Strategi Pembelajaran Kontekstual (Inovatif) (Bandung: Yrama Widya, 2013); Supardi Supardi, Kinerja Guru, vol. 1 (Jakarta: Rajawali Pers PT. RajaGrafindo Persada, 2014); Juhji, Juhji, and Adila Suardi. "Profesi Guru Dalam Mengembangkan Kemampuan Berpikir Kritis Peserta Didik Di Era Globalisasi." Geneologi PAI: Jurnal Pendidikan Agama Islam 5, no. 1 (2018): 16-24; Salim, Herli, and Tri Ilma Septiana. "Survey of Students Satisfaction and Some Efforts to Improve Lecturer Profesionalism in the English Education Department of STKIP Situs Banten." Tarbawi: Jurnal Keilmuan Manajemen Pendidikan 6, no. 01 (2020): 1-10; Fitri, F. I. T. R. I. "Perilaku Organisasi Dan Kepemimpinan Sebagai Sebuah Sistem." Adaara: Jurnal Manajemen Pendidikan Islam 6, no. 1 (2018): 484-497; Syamsuriadi, S. Y. A. M. S. U. R. I. A. D. I. "Self Management Concept Dalam Kepemimpinan Lembaga Pendidikan." Adaara: Jurnal Manajemen Pendidikan Islam 9, no. 2 (2019): 871-879; Abdullah, K. "Model Kepemimpinan Transformasional Kepala Madrasah dan Keberhasilannya terhadap Kualitas Madrasah (Studi pada MTsN Watampone)." Adaara: Jurnal Manajemen Pendidikan Islam 5, no. 1 (2019).

${ }^{8}$ Aqib, Model-Model Media Dan Strategi Pembelajaran Kontekstual (Inovatif); Supardi, Kinerja Guru.

${ }^{9}$ Miftah Thoha, Perilaku Organisasi: Konsep Dasar Dan Aplikasinya (Jakarta: Rajawali Pers, 2007).

${ }^{10}$ Kartini Kartono, Pemimpin Dan Kepemimpinan (Jakarta: Rajawali Pers, 2008).

${ }^{11}$ Kartono.

${ }^{12}$ PB Triton, Manajemen Strtegis Terapan Perusahaan Dan Bisnis (Jakarta: Oryza, 2011).

${ }^{13}$ Husein Umar, Strategic Management in Action (Jakarta: PT. Gramedia Pustaka Utama, 2001).

${ }^{14}$ Mudrajad Kuncoro, Stategi Bagaimana Meraih Keunggulan Kompetitif (Jakarta: Erlangga, 2006). 
melakukan pembinaan manajemen sekolah, penambahan buku, dan sarana belajar dalam rangka menciptakan kegiatan belajar mengajar yang bermutu, pembinaan fisik, dan penampilan sekolah, serta peningkatan partisipasi masyarakat terhadap sekolah yang muara dari berbagai kegiatan ini adalah peningkatan mutu guru. ${ }^{15}$

Kompetensi guru di atas harus didorong untuk dikuasai dengan cara memfasilitasi peningkatan mutu guru, karena hitam-putihnya proses belajar mengajar di dalam kelas banyak dipengaruhi oleh mutu gurunya. ${ }^{16}$ Hal ini perlu dipikirkan oleh berbagai pihak yang berkepentingan, karena keberhasilan penyelenggaraan pendidikan sangat ditentukan oleh mutu guru.

Lahirnya UU No. 14 Tahun 2005 merupakan salah satu usaha untuk meningkatkan mutu guru, sekaligus diharapkan dapat meningkatkan mutu pendidikan di Indonesia. Di dalam UU ini diamanatkan bahwa guru wajib memiliki kualifikasi akademik, kompetensi, sertifikat pendidik, sehat jasmani, dan rohani, serta memiliki kemampuan untuk mewujudkan tujuan pendidikan nasional. Kebijakan prioritas dalam rangka pemberdayaan guru saat ini adalah meningkatkan kualifikasi, peningkatan kompetensi, sertifikasi guru, pengembangan karir, penghargaan dan perlindungan, perencanaan kebutuhan guru, tunjangan guru, dan maslahat tambahan.

Dalam peningkatan mutu guru, tentunya masih ada permasalahan-permasalahan yang harus dipecahkan oleh seorang pemimpin, baik permasalahan internal maupun eksternal, hal ini dikarenakan dinamika kehidupan dalam dunia pendidikan yang selalu berkembang. Solusi seorang pemimpin terhadap permasalahan pada suatu waktu belum tentu relevan di kemudian hari. Oleh karenanya, kepala sekolah di lingkungan pesantren harus memiliki berbagai strategi dalam peningkatan mutu guru. Zahroh menjelaskan beberapa bentuk peningkatan mutu guru dapat dilakukan melalui program peningkatan kualifikasi guru, pemberian tunjangan Profesi Guru, dan program sertifikasi guru. ${ }^{17}$ Sedangkan Suharto menjelaskan empat strategi yang dapat dilakukan oleh kepala sekolah untuk meningkatkan mutu tenaga pendidik di sekolah, yaitu: peningkatan melalui pendidikan dan pelatihan (off the job training), pelatihan dalam melaksanakan tugas atau on the job training, pelatihan lesson study, dan melakukan penelitian tindakan kelas (PTK).

Tulisan ini tentang penelitian tentang mutu guru sekolah yang berada di lingkungan Pesantren Daar el-Qolam yang berarti bahwa sekolah yang menjadi lokus penelitian merupakan salah satu unit lembaga pendidikan dan menjadi bagian integral dari sistem pendidikan pesantren. Dalam sistem pendidikan pesantren modern, sekolah merupakan lembaga formal didirikan sebagai

\footnotetext{
${ }^{15}$ Kuncoro.

${ }^{16}$ Ali Nurdin, 'Manajemen Pembinaan Kepala Sekolah Dan Motivasi Kerja Guru Serta Kemampuan Mengajar Guru Dalam Upaya Meningkatkan Kompetensi Profesional Guru Di Sekolah', Tarbawi: Jurnal Keilmuan Manajemen Pendidikan 5, no. 01 (2019): 49-62, https://doi.org/doi:10.32678/tarbawi.v5i01.1829; Adang Sutarman, I Gusti Putu Wardipa, and Mahri Mahri, 'Penguatan Peran Guru Di Era Digital Melalui Program Pembelajaran Inspiratif', Tarbawi: Jurnal Keilmuan Manajemen Pendidikan 5, no. 02 (2019): 229-38, https://doi.org/doi:10.32678/tarbawi.v5i02.2097.

17 Aminatul Zahroh, Membangun Kualitas Pembelajaran Melalui Dimensi Profesionalisme Guru (Bandung: Yrama Widya, 2008).
} 
dari implementasi sistem ajar yang dicanangkan pesantren. Sehingga berbagai kebijakan yang dikeluarkan oleh sekolah tidak berdiri sendiri akan tetapi merupakan kebijakan yang menyatu dengan kebijakan pesantran yang semuanya bermuara kepada kebijakan pengasuh pesantren atau Kyai sebagai pimpinan tertinggi di dunia pesantren.

\section{METODE}

Penelitian ini menggunakan penelitian lapangan (field research), ${ }^{18}$ dilaksanakan di SMA Daar el-Qolam 2 Gintung, Jayanti, Tangerang. Penelitian ini bersifat deskriptif kualitatif dengan pendekatan fenomenologis. Data yang dikumpulkan terdiri atas data primer dan data sekunder. Data primer adalah data yang dikumpulkan, diolah, dan disajikan oleh peneliti dari sumber pertama, diperoleh dan dikumpulkan secara langsung dari informan melalui pengamatan, catatan lapangan, dan wawancara terhadap pimpinan pesantren, kepala sekolah, kepala bagian SDM, dan tiga orang guru. Sedangkan data sekunder adalah data yang dikumpulkan, diolah, dan disajikan oleh pihak lain yang biasanya disajikan dalam bentuk publikasi dan jurnal berupa dokumen, rekaman, arsip, dan termasuk hasil pengamatan langsung meliputi sejarah sekolah, visi misi sekolah, jangka panjang sekolah, keadaan sarana prasarana sekolah, dan dokumen-dokumen lain yang relevan dengan data yang dibutuhkan dalam penelitian ini.

Teknik pengambilan sampel dalam penelitian kualitatif ini menggunakan teknik sampling yang bersifat selektif dengan menggunakan pertimbangan berdasarkan konsep teoritis yang digunakan, keingintahuan pribadi peneliti, karakteristik empirisnya, dan lain-lain. Oleh karena itu, sampel yang akan digunakan dalam penelitian ini lebih bersifat purposive sampling. Sampel yang ditentukan oleh peneliti adalah enam orang yaitu: 1 orang pemimpin pondok Pesantren, 1 orang kepala sekolah, 1 orang kepala bagian SDM, dan 3 orang guru dari jumlah total guru sebanyak 42 orang. Untuk menjamin keabsahan data, peneliti melakukan uji validitas internal, validitas eksternal, uji reliabilitas, dan uji obyektivitas. Data yang telah terkumpul kemudian dianalisis dengan menggunakan model Miles dan Huberman, yaitu: reduksi data (data reduction), penyajian data (data display), penarikan kesimpulan/verifikasi (conclusion drawing/verification). ${ }^{19}$

\section{HASIL DAN PEMBAHASAN}

\section{Mutu Guru Sekolah di Lingkungan Pesantren}

Guru atau tenaga pendidik merupakan salah satu komponen penting dalam penyelenggaraan pendidikan. Artinya tanpa guru, kegiatan pendidikan tidak akan berjalan karena guru merupakan komponen penting yang keberadaannya tidak tergantikan dengan teknologi modern sekalipun. Karena guru berfungsi bukan hanya sebagai orang yang mentranfer ilmu

\footnotetext{
${ }^{18}$ Lexy J Moleong, Metodologi Penelitian Kualitatif, 32nd ed. (Bandung: Remaja Rosdakarya, 2014)

${ }^{19}$ Sugiyono Sugiyono, Metode Penelitian Manajemen, 4th ed. (Bandung: Alfabeta, 2015).
} 
(knowledge) tapi juga memiliki tugas sebagai pentranfer nilai (value). Keberadaannya sangat menentukan proses pendidikan, dan keahliannya atau profesionalismenya sangat menentukan mutu proses dan hasil pendidikan. Pendidikan yang bermutu hanya dihasilkan oleh proses yang mutu pula. Proses yang bermutu ditentukan oleh guru yang bermutu.

Berdasarkan hasil penelitian terhadap mutu guru SMA di Lingkungan Pesantren, yaitu: SMA Daar el-Qolam menunjukkan bahwa guru SMA Daar el-Qolam memiliki kualifikasi akademik sarjana (S1) dan sebagian memiliki kualifikasi magister (S2) dengan rincian sarjana sain 100 persen mengajar sesuai dengan bidangnya dan untuk guru sosial 80 persen guru mengajar sesuai dengan bidangnya, sisanya 20 persen mata pelajaran ilmu sosial diampu oleh guru yang bukan bidangnya. Dari 42 orang guru yang mengajar di SMA Daar el-Qolam, ada 17 orang guru yang telah memiliki sertifikat pendidik dan sisanya 25 orang belum tersertifikasi. Hal ini menunjukkan bahwa guru bersertifikat profesi atau guru profesional masih kurang dari ketentuan, disamping itu masih terdapat beberapa guru yang mengajar tidak sesuai dengan bidangnya. Terjadi mismatch antara bidang yang keahlian dengan bidang yang diajarkan, khususnya bidang Ilmu Pengetahuan Sosial sekitar 20 persen. Padahal untuk menjadi guru yang bermutu minimal memiliki tiga kriteria, yaitu: memiliki kualifikasi akademik sarjana, tersertifikasi oleh pemerintah, dan menguasai materi atau konten akademik yang diajarkan. ${ }^{20}$ Guru harus dapat menguasai bahan ajar, mengelola pembelajaran, memanaj kelas, mengusai dan menggunakan IT dalam proses pembelajaran, memiliki kemampuan melaksanakan pembelajaran aktif (active learning), menguasai konsep pendidikan, mahir menilai dan melakukan evaluasi pembelajaran, dan lainlain. ${ }^{21}$ Secara sederhana dapat disimpulkan bahwa guru profesional harus memiliki empat kompetensi, yaitu meliputi: kompetensi pedagogik, sosial, kepribadian, dan profesional. Abin menambahkan bahwa indikator guru bermutu adalah tenaga pengajar yang mampu melahirkan lulusan yang bermutu, sesuai dengan kebutuhan penyelenggaraan berbagai jalur, jenis, dan jenjang pendidikan. ${ }^{22}$

Apabila mengacu kepada pendapat Nwogu dan Abin di atas menunjukkan bahwa indikator guru yang profesional dan bermutu belum tercapai. Dapat dikatakan juga bahwa guru bermutu yaitu guru yang dapat mencetak dan menjadikan peserta didik sesuai dengan yang diharapkan oleh lembaga pendidikan dan orang tua siswa, melakukan pembelajaran terhadap siswa dengan memiliki kualifikasi tingkat sarjana, sertifikasi dari negara, dan memiliki kompetensi akademik sesuai bidangnya. Berdasarkan penjelasan di atas dapat disimpulkan bahwa guru SMA Daar el-Qolam ada yang bermutu dan ada yang belum bermutu.

\footnotetext{
${ }^{20}$ U. J Nwogu and B. I Esobhawan, 'Teacher Quality and Quantity: Implementations for the Implementation of Universal Basic Education in Nigeria', Academic Research International 5, no. 1 (2014): 199-208.

${ }^{21}$ Abdul Hadis and B. Nurhayati, Manajemen Mutu Pendidikan, 3rd ed. (Bandung: Alfabeta, 2014).

22 Abin Abin and Syamsuddin Makmun, Psikologi Kependidikan (Bandung: PT. Remaja Rosdakarya, 2012).
} 


\section{Strategi Peningkatan Mutu Guru Sekolah di Lingkungan Pesantren}

Guru yang tidak profesional dan tidak bermutu akan berdampak kepada mutu pembelajaran. Padahal, Core business dunia pendidikan adalah pembelajaran. Proses pembelajaran akan bermutu jika guru sebagai eksekutor utama dalam pembelajaran juga bermutu. Upaya meningkatkan mutu guru merupakan aspek strategis dalam memperbaiki mutu layanan pendidikan. Untuk meningkatkan mutu guru sekolah diperlukan strategi yang tepat agar guru yang bermutu dapat dicapai. Pada tahap ini, pimpinan puncak lembaga dituntut untuk fokus pada tujuan jangka panjang lembaga dengan terus meningkatkan mutu guru melalui penyusunan rencana dan menemukan cara untuk mencapai tujuan tersebut. ${ }^{23}$

Pimpinan pesantren dan kepala SMA Daar el-Qolam juga menyadari pentingnya peningkatan guru dalam upaya meningkatkan mutu lembaganya. Hal tersebut dapat dilihat dari adanya beberapa strategi peningkatan mutu guru yang dilakukan pemimpin pesantren dan sekolah melalui penyusunan rencana dan cara pencapaiannya. Strategi untuk meningkatkan mutu guru sekolah di lingkungan pesantren tersebut dilakukan melalui beberapa program, yaitu: program peningkatan kompetensi guru, supervisi kelas, pembentukan kelompok musyawarah guru mata pelajaran (MGMP), dan penguatan karakter guru ${ }^{24}$ dengan cara pelatihan dan penugasan.

Pernyataan di atas diperkuat oleh Kepala Sekolah sebagai eksekutor berbagai kebijakan dengan mengatur strategi pencapaian tujuan pesantren. Walaupu datangnya strategi bisa dari pimpinan pesantren (top down) ataupun dari kepala sekolah (bottom up). Beberapa strategi peningkatan guru sekolah di lingkungan pesantren SMA Daar el-Qolam, yaitu: Pertama, supervisi guru baik dilakukan oleh kepala sekolah maupun oleh pemimpin pondok; Kedua, bagi guru yang belum mampu dalam proses pembelajaran setelah dievaluasi (khususnya guru dalam masa pengabdian), untuk mengikuti pelatihan-pelatihan di bidangnya masing-masing atau dibimbing oleh guru-guru yang ahli di bidangnya. Ketiga, izin belajar ke jenjang S1 (bagi guru lulusan Pesantren Daar el-Qolam yang dalam masa pengabdian) dan bagi yang memiliki kualifikasi sarjana dapat melanjutkan ke jenjang magister (S2).

Hal tersebut senada dengan apa yang diungkapkan oleh Kepala Bagian Pengembangan SDM, beliau mengatakan bahwa strategi Pimpinan Pondok Pesantren dalam meningkatkan mutu guru SMA Daar el-Qolam, diantaranya: mengadakan program pelatihan dan pengiriman guru untuk studi ke luar negeri. ${ }^{25}$ Pimpinan pesantren adalah jabatan atau posisi seseorang di dalam sebuah pondok pesantren yang dapat membuat kebijakan pada jalur ajar dan jalur asuh. Pimpinan Pondok Pesantren merupakan salah satu faktor yang dapat mendorong sekolah untuk dapat mewujudkan visi, misi, tujuan, dan sasaran melalui sebuah strategi yang dilaksanakan secara terencana dan bertahap. Secara garis besar, strategi peningkatan mutu guru sekolah di Pesantren Daar el-Qolam

\footnotetext{
${ }^{23}$ Umar, Strategic Management in Action.

${ }^{24}$ Umar.

${ }^{25}$ Tata Suwanta, Program Pelatihan dan Pengiriman Guru, 2018.
} 
dapat dirinci sebagai berikut: program pelatihan guru, program supervisi kelas, program pembentukan MGMP (Musyawarah Guru Mata Pelajaran) yang fungsinya untuk sharing antar guru mata pelajaran, program pembinaan karakter guru dengan cara pelatihan dan penugasan, dan program perbaikan pembelajaran melalui penelitian tindakan kelas (PTK).

\section{Faktor Problematika Peningkatan Mutu Guru Sekolah di Pesantren}

Beberapa problem yang dapat ditemui dalam upaya peningkatan mutu guru sekolah di pesantren terjadi secara alamiyah. Kondisi ini diwajarkan dalam pelaksanaan suatu program di mana pun termasuk di pesantren. Demikian juga dalam peningkatan mutu guru di SMA Daar elQalam. Didasarkan atas wawancara penulis terhadap beberapa narasumber, dipahami bahwa dalam upaya peningkatan mutu guru sekolah di SMA Daar el-Qalam terdapat faktor pendukung dan penghambat.

Faktor pendukungnya seperti: sarana dan prasarana yang cukup lengkap dalam upaya mendukung kegiatan proses pembelajaran, pelatihan yang cukup dan berkelanjutan, serta motivasi pimpinan pondok pesantren kepada para guru yang bermutu. Sedangkan faktor penghambat diantaranya adalah: adanya guru yang kurang cepat menerima pembaharuan, kesempatan dalam mengup-grade pengetahuan, lingkungan belajar, waktu pelatihan.

Meskipun terdapat faktor pendukung dan penghambat dalam upaya peningkatan mutu guru di pesantren sebagaimana diuraikan di atas, pimppinan pondok pesantren Daar el-Qalam tetap melakukan evaluasi dan penilaian secara komprehensif terhadap program yang dijalankan dengan terus mengoptimalkan sarana dan prasarana yang mendukung kegiatan proses pembelajaran sehingga dapat tercapai dan tepat sasaran dalam penggunaannya. Selain itu, sebagai bentuk evaluasi, pimpinan pondok juga memberikan semangat (ruh) kepada para guru agar selalu dan terus mengoptimalkan potensi yang ada di pondok pesantren.

Dengan begitu, apa yang telah dilaksanakan oleh pimpinan pondok terhadap beberapa faktor pendukung dan penghambat dalam upaya meningkatkan mutu guru seirama dengan pendapatnya Crown bahwa pada prinsipnya strategi dapat dibagi ke dalam tiga tahap yakni: 1) formulasi, 2) implementasi strategi, dan 3) evaluasi strategi. ${ }^{26}$

\section{Upaya dan Langkah Strategis dalam Meningkatkan Mutu Guru Sekolah}

Didasarkan atas data yang telah diuraikan di atas, dapat dipahami bahwa upaya dan langkah strategis yang dapat dilakukan oleh pimpinan pondok Daar el-Qalam adalah sebagai berikut:

${ }^{26}$ Agustinus Sri Wahyudi, Manajemen Strategik: Pengantar Proses Berfikir Strategik (Bandung: Binarupa Aksara, 2013). 
Pembinaan Mutu Guru. Pimpinan pondok pesantren Daar el-Qalam dalam upaya meningkatkan mutu guru sekolah di pesantren telah menjalankan fungsinya secara baik dengan cara mengikutsertakan para guru dalam kegiatan workshop dan atau seminar-seminar profesi guru, baik yang diselenggarakan di lingkungan pesantren maupun di luar pesantren (pemerintah daerah, diknas, kemenag) dengan harapan para guru mendapatkan informasi dan ilmu baru agar kualitasnya menjadi semakin baik.

Pengawasan Mutu Guru. Pengawasan dilakukan secara langsung oleh pimpinan pondok pesantren Daar el-Qalam atau pun dengan mendelegasikan kepada kepala sekolah dalam kegiatan supervisi kelas (kegiatan supervisi kepala sekolah di kelas saat guru mengajar) sehingga pimpinan pondok mendapatkan gambaran yang jelas dalam melihat kualitas para gurunya. Dengan demikian pimpinan dalam mengetahui apa saja kelemahan dan kekurangan yang terdapat pada gurunya atau dibutuhkan guna membantu meningkatakan mutu para gurunya.

Penyediaan Sarana Prasarana. Penyediaan sarana dan prasarana yang dilakukan pimpinan pondok pesantren Daar el-Qalam dengan cara melengkapi gedung perpustakaan, perangkat pembelajaran dan jaringan internet di segala penjuru pondok pesantren. Ini dilakukan dalam upaya meningkatkan mutu guru di pesantren.

Penanaman Komitmen. Upaya dan langkah strategis selanjutnya yang dapat dilakukan pimpinan pondok pesantren Daar el-Qalam adalah membangkitkan ruh atau jiwa guru dalam mendidik dan mengajar. kegiatan ini dilakukan di awal tahu pelajaran baru dan saat evaluasi bulanan dengan harapan adanya peningkatan komitemen dan mutu yang semakin baik.

Pemberian Tunjangan. Upaya dan langkah strategis yang berikutnya adalah pemberian tunjangan guru. pemberian tunjangan guru diberikan pimpinan pondok pesantren Daar el-Qalam dengan harapan adanya peningkatan mutu guru di SMA Daar el-Qalam. Pemberian tunjangan ini melalui sistem salary yang telah disepakati dan ditetapkan pihak pesantren.

Berdasarkan fakta dan data di atas, bahwa berbagai upaya dan langkah-langkah strategis pimpinan pondok pesantren dalam menjawab permasalahan yang ada dalam peningkatan mutu guru antara lain dengan: 1) pembinaan mutu guru, 2) pengawasan mutu guru, 3) penyediaan sarana dan prasarana, 4) penanaman komitmen, dan 5) pemberian tunjangan.

Dengan demikian, bahwa upaya dan langkah strategis yang dilakukan pimpinan pondok pesantren Daar el-Qalam sejalan dnegan pendapatnya Zahroh ${ }^{27}$ bahwa kiat-kiat dalam upaya peningkatan mutu guru dapat dilakukan dengan: 1) manajemen guru di lembaga formal, 2) rekrutmen dan pemberdayaan guru, 3) program peningkatan kualifikasi guru, 4) tunjangan profesi guru, dan 5) program sertifikasi guru.

Begitu pula dengan pimpinan pondok pesantren Daar el-Qalam yang telah menjalankan peran, tugas, dan fungsinya sebagai pimpinan puncak organisasi (top leader). Ini sejalan dengan

\footnotetext{
${ }^{27}$ Zahroh, Membangun Kualitas Pembelajaran Melalui Dimensi Profesionalisme Guru.
} 
pendapatnya Kartono ${ }^{28}$ bahwa fungsi kepemimpnan adalah memandu, menuntun, membimbing, membangun, memberi atau membangunkan motivasi kerja, mengemudikan organisasi, menjalin jaringan-jaringan komunikasi yang baik, memberikan supervisi/pengawasan yang efisien, dan membawa para pengikutnya kepada sasaran yang ingin dituju, sesuai dengan ketentuan waktu dan perencanaan. Sedangkan tugas pemimpin ialah pemberian insentif terhadap bawahannya sebagai motivasi untuk bekerja lebih giat, baik insentif materiil maupun insentif sosial (imaterill). Insentif materiil dapat berbentuk uang, sekuritas fisik, jaminan sosial, jaminan kesehatan, premi, bonus, kondisi kerja yang baik, pensiun, fasilitas tempat tinggal yang menyenangkan, dan lain-lain. Sedangkan insentif sosial dapat berupa promosi jabatan, status sosial tinggi, martabat diri, prestise sosial, dan respek.

\section{UCAPAN TERIMA KASIH}

Penulis mengucapkan terimakasih yang sebesar-besarnya atas diterbitkannya tulisan ini, terutama kepada tim editor Adaara: Jurnal Manajemen Pendidikan Islam Institut Agama Islam Negeri (IAIN) Bone.

\section{KESIMPULAN DAN SARAN}

Strategi dalam meningkatkan mutu guru sekolah di lingkungan pesantren dapat dilakukan dengan cara: 1) pembinaan mutu guru, 2) pengawasan mutu guru, 3) penyediaan sarana dan prasarana, 4) penanaman komitmen, dan 5) pemberian tunjangan.

\section{DAFTAR RUJUKAN}

Abdullah, K. (2019). Model Kepemimpinan Transformasional Kepala Madrasah Dan Keberhasilannya Terhadap Kualitas Madrasah (Studi pada MTsN Watampone). Adaara: Jurnal Manajemen Pendidikan Islam, 5(1).

Abin, A., \& Makmun, S. (2012). Psikologi Kependidikan. PT. Remaja Rosdakarya.

Adha, M. A., Supriyanto, A., \& Timan, A. (2019). Strategi peningkatan mutu lulusan madrasah menggunakan diagram fishbone. Tarbawi: Jurnal Keilmuan Manajemen Pendidikan, $5(01), 11-22$.

Amin, M. (2017). Impelemntasi Manajemen Strategis Kepala Sekolah Menengah Pertama di Kabupaten Serang. Tarbawi: Jurnal Keilmuan Manajemen Pendidikan, 2(02), 41-57.

Apud, A. (2018). Manajemen mutu pendidikan man insan cendekia. Tarbawi: Jurnal Keilmuan Manajemen Pendidikan, 4(02), 171-190.

Apud, A. (2020). Pengembangan Profesi Guru Madrasah Swasta di Kota Serang. Nidhomul Haq: Jurnal Manajemen Pendidikan Islam, 5(1), 62-79.

\footnotetext{
${ }^{28}$ Kartono, Pemimpin Dan Kepemimpinan.
} 
Aqib, Z. (2013). Model-Model Media Dan Strategi Pembelajaran Kontekstual (Inovatif). Yrama Widya.

Budi, A. M. S., \& Apud, A. (2019). Peran Kurikulum Kulliyatul Mu'allimin Al-Islamiyah (KMI) Gontor 9 dan Disiplin Pondok dalam Menumbuhkembangkan Karakter Santri. Tarbawi: Jurnal Keilmuan Manajemen Pendidikan, 5(01), 1-10.

Dwiyama, F. (2018). Unsur Manajemen dalam Pengelolaan Lembaga Pendidikan Islam di Indonesia. Adaara: Jurnal Manajemen Pendidikan Islam, 7(1), 675-695.

Dwiyama, F. (2018). Manajemen Berbasis Madrasah dalam Peningkatan Mutu dI MTsN Watampone Kabupaten Bone. Adaara: Jurnal Manajemen Pendidikan Islam, 6(1), 535554.

Dwiyama, F. (2019). Pengembangan Lembaga PAUD melalui Implementasi Manajamen Berbasis Sekolah. Adaara: Jurnal Manajemen Pendidikan Islam, 8(1), 797-815.

Fitri, F. (2018). Perilaku Organisasi Dan Kepemimpinan Sebagai Sebuah Sistem. Adaara: Jurnal Manajemen Pendidikan Islam, 6(1), 484-497.

Gaspersz, V. (2008). Total Quality Managament. Gramedia Pustaka Utama.

Hadis, A., \& Nurhayati, B. (2014). Manajemen Mutu Pendidikan (3rd ed.). Alfabeta.

Hasbullah, H., Juhji, J., \& Maksum, A. (2019). Strategi belajar mengajar dalam upaya peningkatan hasil belajar pendidikan agama islam. Edureligia; Jurnal Pendidikan Agama Islam, 3(1), $17-24$.

Istofa, D. N., \& Zulyanty, M. (2018). Perencanaan Guru Madrasah Aliyah Jambi dalam Pembelajaran Matematika pada Kurikulum Tingkat Satuan Pendidikan. ANARGYA: Jurnal Ilmiah Pendidikan Matematika, 1(2), 103-109.

Juhji, J. (2015). Telaah Komparasi Konsep Pembelajaran menurut Imam Al-Zarnuji dan Imam AlGhozali. Tarbawi: Jurnal Keilmuan Manajemen Pendidikan, 1(02), 17-26.

Juhji, J. (2016). Peran Urgen Guru dalam Pendidikan. Studia Didaktika, 10(01), 51-62.

Juhji, J. (2017). Profesi Pendidik dan Tenaga Kependidikan. Serang: Pusat Penelitian dan Penerbitan LP2M IAIN Sultan Maulana Hasanuddin Banten.

Juhji, J., \& Suardi, A. (2018). Profesi Guru Dalam Mengembangkan Kemampuan Berpikir Kritis Peserta Didik Di Era Globalisasi. Geneologi PAI: Jurnal Ilmiah Bidang Pendidikan Agama Islam, 5(1), 16-24.

Juhji, J. (2019). Analyzing Madrasah Ibtidaiyah Teacher Candidates Skill of Technological Pedagogical Content Knowledge on Natural Science Learning. Al Ibtida: Jurnal Pendidikan Guru MI, 6(1), 1-18.

Juhji, J., \& Nuangchalerm, P. (2020). Interaction between science process skills and scientific attitudes of students towards technological pedagogical content knowledge. Journal for the Education of Gifted Young Scientists, 8(1), 1-16. 
Kartono, K. (2008). Pemimpin dan Kepemimpinan. Rajawali Pers.

Kuncoro, M. (2006). Stategi Bagaimana Meraih Keunggulan Kompetitif. Erlangga.

Kuswaeri, I. (2016). Kepemimpinan Transformasional Kepala Sekolah. Tarbawi: Jurnal Keilmuan Manajemen Pendidikan, 2(02).

Moleong, L. J. (2014). Metodologi Penelitian Kualitatif (32nd ed.). Remaja Rosdakarya.

Muhammadi, N., bin Hj Marzuki, S. C., \& bin Mohd Hussin, M. Y. (2017). Kepemimpinan Transformasional Kepala Madrasah, Prestasi Guru Dan Budaya Belajar Dalam Meningkatkan Mutu Madrasah Tsanawiyah Negeri Jakarta Selatan Transformational Leadership Madrasah Principal, Teacher Achievement and Learning Culture in Improving Qualit. Tarbawi: Jurnal Keilmuan Manajemen Pendidikan, 1(01), 49-61.

Mu'izzuddin, M., Juhji, J., \& Hasbullah, H. (2019). Implementasi Metode Sorogan dan Bandungan dalam Meningkatkan Kemampuan Membaca Kitab Kuning. Geneologi PAI: Jurnal Ilmiah Bidang Pendidikan Agama Islam, 6(1), 43-50.

Mulyani, N. (2019). Pengembangan profesionalisme guru pada mtsn 1 serang melalui peningkatan kompetensi profesional dan pedagogik. Tarbawi: Jurnal Keilmuan Manajemen Pendidikan, 5(01), 87-96.

Noor, W., \& Juhji, J. (2020). Integrasi Budaya Prestasi pada Fungsi Perencanaan Pembinaan Mutu Dosen. AL-TANZIM: Jurnal Manajemen Pendidikan Islam, 4(1), 1-12.

Nwogu, U. J., \& Esobhawan, B. I. (2014). Teacher Quality and Quantity: Implementations for the implementation of Universal Basic Education in Nigeria. Academic Research International, 5(1), 199-208.

Rosad, A. M. (2019). Implementasi Pendidikan Karakter Melalui Managemen Sekolah. Tarbawi: Jurnal Keilmuan Manajemen Pendidikan, 5(02), 173-190.

Rouf, A. (2019). Kepemimpinan Kepala Madrasah dalam Meningkatkan Etos Kerja Guru Pada MTs Pondok Besar Roudlotul Mubtadiin Balekambang Nalumsari Jepara Tahun Pelajaran 2017/2018. Tarbawi: Jurnal Keilmuan Manajemen Pendidikan, 5(01), 97-114.

Royhatudin, A., \& Supardi, J. Transformational Leadership Style in Implementing Madrasa Based Management.

Salim, H., \& Septiana, T. I. (2020). Survey of Students Satisfaction and Some Efforts to Improve Lecturer Profesionalism in the English Education Department of STKIP Situs Banten. Tarbawi: Jurnal Keilmuan Manajemen Pendidikan, 6(01), 1-10.

Sugiyono, S. (2015). Metode Penelitian Manajemen (4th ed.). Alfabeta.

Supardi, S. (2014). Kinerja Guru (Vol. 1). Rajawali Pers PT. RajaGrafindo Persada.

Supardi, S. (2017). Peran Kepemimpinan dan Keterlibatan Group Decission Making dalam Perubahan Organisasi. Tarbawi: Jurnal Keilmuan Manajemen Pendidikan, 1(01), 37-48. 
Surani, D., \& Mifthahudin, M. (2018). Kompetensi Guru dan Motivasi Mengajar Guru Berpengaruh terhadap Efektivitas Pembelajaran di SMK Negeri 3 Kota Serang. Tarbawi: Jurnal Keilmuan Manajemen Pendidikan, 4(02), 149-158.

Sutarman, A., Wardipa, I. G. P., \& Mahri, M. (2019). Penguatan Peran Guru di Era Digital Melalui Program Pembelajaran Inspiratif. Tarbawi: Jurnal Keilmuan Manajemen Pendidikan, 5(02), 229-238.

Syamsuriadi, S. (2019). Self Management Concept Dalam Kepemimpinan Lembaga Pendidikan. Adaara: Jurnal Manajemen Pendidikan Islam, 9(2), 871-879.

Suwanta, T. (2018). Program Pelatihan dan Pengiriman Guru [Personal communication].

Thoha, M. (2007). Perilaku Organisasi: Konsep Dasar dan Aplikasinya. Rajawali Pers.

Triton, P. (2011). Manajemen Strtegis Terapan Perusahaan dan Bisnis. Oryza.

Umar, H. (2001). Strategic Management in Action. PT. Gramedia Pustaka Utama.

Venkatesh, V., \& Davis, F. D. (2000). A Theoretical Extension of the Technology Acceptance Model: Four Longitudinal Field Studies. Management Science, 46(2), 186-204.

Wahyudi, A. S. (2013). Manajemen Strategik: Pengantar Proses Berfikir Strategik. Binarupa Aksara.

Zahroh, A. (2008). Membangun Kualitas Pembelajaran melalui Dimensi Profesionalisme Guru. Yrama Widya. 